\title{
A reinvenção dos corpos: por uma Pedagogia da Complexidade
}

ADROALDO GAYA*

Viva cada instante, Viva cada momento

Proteja da razão teus sentimentos Tente ser feliz Enquanto a tristeza estiver distraída. (Toquinho, 2005)

1- Introdução

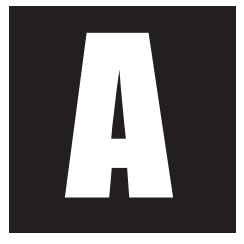

s dúvidas e inquietações são como os ventos. Sopram e fazem nosso espírito transcender em seu discurso. Discurso que tem a pretensão de ser preciso. Escrever é preciso. Preciso de precisão. Exige cortar os excessos. ${ }^{1}$ Navegar no curso ou transcender no discurso também se faze preciso. Preciso de necessidade. Mas, tal como do navegador se exige que saiba conduzir no contravento e navegar na contracorrente, solicita-se de quem escreve que saiba fazê-lo no contraponto. Escrever e discursar requerem explicitar o contraditório. "Tendências contrárias não rompem a unidade, equilibram-se, ao contrário, para garantir a atuação do conjunto" "(SCHÜLLER, 2001, p.223).

\footnotetext{
* Professor e Coordenador do Programa de Pós-graduação em Ciências do Movimento Humano da UFRGS. Brasil 1 É importante recordar que a palavra " preciso" origina-se do latim "praeciso" que significa cortar os excessos, cortar pelas extremidades.

2 GAYA, A. Discursos sobre o corpo ausente. In. Lebre.E \& Bento,J. Professor de Educação Física. Ofícios da Profissão. Porto: FCDEF.UP. 2004, ps $163-174$.

3 In. Heráclito e seu (dis)curso. Porto Alegre, L\&PM, 2001, p. 223.
} 
Ora! A pretensão do discurso hegemônico é, ela mesma, arbitrária. Contradizer. Dialogar é o que se pretende neste ensaio. Afinal, trata-se dos desafios da complexidade. Eis o propósito: no contraponto da pedagogia tradicional, anunciar o discurso sobre o corpo ausente na educação escolar. Em outras palavras: denunciar o (dis)curso que esconde a ausência do corpo humano, paradoxalmente, em defesa do ser humano. Contradizer o humanismo sem corpo. Mais do que isso, contestar o pós-humanismo radical a anunciar, para breve, a absoluta insolvência do corpo humano.

Orientamos nossas reflexões a partir da seguinte hipótese: Em tempos pós-modernos, o discurso filosófico aponta para a superação da racionalidade iluminista. As propostas pedagógicas procuram perspectivas interdisciplinares, novas formas de configuração curricular e de organização do espaço escolar. Muito seguidamente ouvem-se referências a uma pedagogia da complexidade. Todavia, paradoxalmente, é nessa mesma escola e no âmbito dessa mesma pedagogia que o paradigma do racionalismo iluminista inspirador de uma educação intelectualista permanece, entre outras evidências, assumindo a herança cartesiana que concebe o corpo como simples extensão da mente.

Três temas compõem os argumentos em defesa da hipótese orientadora: (1) Nas escolas de nosso tempo, o corpo, considerado como res extensa, permanece passivo, disciplinado e distante dos interesses de uma pedagogia predominantemente intelectualista. Enfim, o corpo não vai à escola; (2) as principais correntes epistemológicas sobre a origem do conhecimento, da mesma forma, limitam-se a expressões de um conhecimento predominantemente racional, dessa forma, o corpo permanece ausente de interesse epistemológico. É o cérebro num barril; (3) uma pedagogia que se limita ao exclusivamente racional é míope e, por consequência, não pode exigir configurar-se numa pedagogia da complexidade. É necessário reivindicar o lugar dos corpos na escola. É a reinvenção dos corpos. 


\section{O corpo não vai à escola}

Mas, se eu tivesse por alguns minutos a oportunidade de intervir no planejamento de uma nova concepção de escola não teria dúvida: levaria o corpo para as salas de aula.

Nas atividades escolares, não há lugar para a cultura corporal. Não há brincadeiras, jogos e outras atividades que ocorrem além dos muros da escola e que fazem parte do saber de crianças e jovens. A escola ao negar essas atividades, nega também o corpo e, ao fazê-lo nega, por consequência seus conhecimentos, movimentos, ritmos, percepções e linguagem. (Altieri, 2005, p.3)

Nenhum sistema educativo, nenhuma pedagogia pode cumprir integralmente sua tarefa se deixar do lado de fora dos muros escolares o corpo. Se a educação física e a educação artística fossem disciplinas centrais nos programas escolares, então, provavelmente, teríamos uma pedagogia a tratar do corpo sensível, corpo expressivo, corpo esportivo. Corpo! Sim, alma e espírito encarnados. É o corpo repleto de emoções, é o ser humano na sua plenitude. Este corpo repleto de significados é um corpo humano que aprende com facilidade a expressar-se no discurso, aprende com facilidade o raciocínio formal, aprende com facilidade a fazer contas, escrever sua história e a conhecer as ciências e as filosofias. É o corpo no mundo. É o corpo vivido. É a expressão mais evidente da complexidade organizacional.

Todavia o discurso pedagógico contemporâneo tão rico em intenções e inovações e que tanto exalta relações de necessária interdisciplinaridade, pluridisciplinaridade, transdisciplinaridade e complexidade, permanece míope. É uma visão míope reduzir o ensino escolar apenas à formação do res cogitans. Ora, não há mente, não há razão e não há espírito que não estejam encarnados. Sou corpo. Corpo vivido. Sou sentimentos, emoções e razões num corpo humano. 
Mas, sabemos todos, nosso ensino tradicional é prioritariamente razão. Fala-se em complexidade, mas o corpo não vai à escola. Talvez vá, mas permanece sentado, disciplinado no silêncio e passividade de uma estátua de mármore. Ou, quem sabe, tal como marionete. Move-se por mecanismos articulados a partir de um conjunto de fios que se mantém sob o controle dos professores. Crianças e adolescentes imóveis nos bancos escolares a suportar uma ladainha sem fim. São letras e números que se combinam em textos de diversas disciplinas, que são dissecadas e devem penetrar pelos olhos, ouvidos de um corpo inerte. Como sugere Freire (1982), estabelece-se a cultura do silêncio corporal. De fato, no discurso fala-se em complexidade, mas, na prática pedagógica, reduz-se o humano exclusivamente ao racional. Corpo estátua de mármore que sequer, como imaginava Condilac (1993), tem, através da educação, seus sentidos despertados um a um. Corpo aprisionado, imóvel e de costas para o mundo, vendo sombras na parede e tomando-as pela realidade, tal como na alegoria da caverna de Platão. Corpo disciplinado, ordenado, de forma que seus sentimentos, suas emoções não penetrem no mundo demasiado humano da suprema razão. Corpo desprezado. Corpo sem sentido. Razão sem corpo. Enfim uma pedagogia que acaba por resumir sua anunciada complexidade ao res cogitans. Descarta Descartes no discurso, mas o acata na prática. Fecha-lhe a porta, mas convida-o a entrar pela janela. A pedagogia tradicional acaba por desconhecer, o que nos diz António Damásio:

A vida tem lugar dentro da fronteira que define o corpo. A vida e a urgência de viver existem no interior duma fronteira, a parede seletivamente permeável que separa o ambiente interno do ambiente externo. A idéia de organismo gira em volta da existência dessa fronteira. (...) Se não há fronteira não há corpo e se não há corpo não há organismo. (...) Para cada pessoa um corpo, para cada corpo uma mente, -um primeiro 
princípio .(..) A mente é de tal forma modelada pelo corpo e destinada a servi-lo que uma mente apenas pode surgir nele. Sem corpo nada de mente. (Damásio, 2000, ps.163, 170 e 172).

Morin (2003), em Introdução ao Pensamento Complexo, sugere uma relação interessante entre os sentidos que podem ser atribuídos às expressões racionalização e racionalidade. A racionalidade é o diálogo incessante entre nosso espírito que cria estruturas lógicas e que as aplica sobre o mundo real. Todavia, sublinha o autor, devemos perceber que, quando esta lógica é insuficiente, temos de admitir que nosso sistema lógico é insuficiente. A racionalização, pelo contrário, consiste em querer encerrar a realidade num sistema coerente, e tudo o que contradiz este sistema coerente é desviado, esquecido, posto de lado, visto como ilusão ou aparência. É assim, hegemonicamente centrada na racionalização, que se ensina na maioria de nossas escolas. Portanto, nesta perspectiva, paradoxalmente, o mundo real não deixa de ser uma abstração. Sua realidade se manifesta exclusivamente por algoritmos, equações e modulações lógicas que necessariamente precisamos aprender, mesmo que, como afirma Rubem Alves (2005, p.73), isto tenha pouco ou quase nenhum sentido para o nosso viver. Portanto, fora disso, parece, não há conhecimento possível. Não há um mundo real para além das sombras sobre a parede ao fundo da caverna da alegoria platônica. Por consequência, neste mundo virtual de nossa escola real, meu corpo não é meu corpo no mundo, é um avatar, é uma transfiguração, é uma metamorfose que muito bem pode existir, desde que fora do mundo real. Meu corpo, marionete; nossa escola, expressão de uma humanidade sem corpos.

Na escola, com muita frequência não se considera a relevância do corpo na definição dos planos de ensino. No entanto, como afirma Michel Serres: 
Todas as diferenças possíveis, tais como o pão e vinho, arroz e cerveja, pedra e bronze, enxada e roda, encontram-se resumidas em meu corpo, no seu corpo e no corpo de todos. Tudo advém dele, é concebido a partir dele, separa-se dele, especifica-se nele; tudo brota dele como de uma fonte eternamente jovem. Nosso corpo, um tronco sem galhos, coberto pelas ramagens culturais.(Serres, 2005, p.64).

Mas meu corpo, este corpo de carne, ossos e vísceras; este corpo que joga, dança, faz esportes, canta, interpreta e representa histórias; este corpo mais ou menos bonito ou feio; mais ou menos forte ou fraco, mais ou menos mais habilidoso; mais ou menos feliz ou triste; mais ou menos deprimido ou ansioso; este corpo, sempre carente de aprendizagens, vive o mundo real. É a minha forma estar no mundo. Assim, por mais que a arrogante prepotência de ser racional queira negar minha corporalidade, sou antes de tudo um corpo no mundo. Como afirma Damásio (2000) não há mente sem corpo. Portanto, é chegada a hora de a escola e sua pedagogia o acolherem e o reconhecerem na plenitude de sua presença.

Ora, se nossa escola mantém o corpo subalterno à razão, como imaginar uma pedagogia da complexidade. Qual será, nesta escola tradicional, o papel da educação física e da educação artística? Adestrá-lo? Submetêlo ao silêncio das emoções e sentimentos em prol de uma racionalidade absoluta? Apenas exercitá-lo com a finalidade exclusiva de consumir seu excesso de energia em prol de uma racionalidade serena e plenamente objetiva? Ou fazê-lo brincar, dançar, cantar e jogar com o intuito de apenas dar repouso à razão? Ou, pior do que isso, ameaçá-lo: só brinca se realizar os deveres. (ALTIERI, 2005, p. 21). Que dialética é esta? Que complexidade se expressa nesta pedagogia que tudo reduz ao ser racional? Ou melhor, como sugere Morin, reduz-se à racionalização. Tudo isso é muito sério para permanecer sem uma revolução que dê ao corpo humano e, por conse- 
guinte ao próprio humano, a dignidade que merece. Tudo isso é muito simplificador e reducionista para suportar o discurso da complexidade. Já é hora de a educação física e a educação artística assumirem seu protagonismo na formação dos nossos escolares. Já é hora, definitivamente, de uma pedagogia da complexidade para além dos discursos estritamente racionalistas. É chegada a hora de reinventar os corpos.

Todavia é necessário perceber, para além das declarações de boas intenções, que convivemos efetivamente num tempo que se anuncia como após a modernidade. Nesse tempo presume-se: (1) que os discursos apontam para a superação do paradigma iluminista; (2) que as propostas pedagógicas procuram perspectivas interdisciplinares; (3) que novas formas de configuração curricular e de organização do espaço escolar se fazem mister. Todavia ressaltamos: é nesta contemporaneidade que o paradigma do racionalismo iluminista, inspirador da primazia de uma educação intelectualista, mantém a herança cartesiana que concebe o corpo como extensão da mente. Em síntese: na escola, o corpo permanece como simples extensão da mente, tal como expressou Descartes em suas "Meditações sobre a Primeira Filosofia".

Uma pedagogia da complexidade não pode suportar tal dualismo. Se bem é verdade que Platão, em Fédon (1972), deu ao corpo o significado de prisão da alma; Descartes, em Meditações (1973), conferiu-Ihe o sentido de um relógio; Lock, no Ensaio Acerca do Entendimento Humano (1973), deu-Ihe o sentido de uma tábua rasa; se hoje filósofos pós-humanistas ${ }^{4}$ anunciam para breve a obsolência do corpo humano, ${ }^{5}$ por outro lado, encontramos em autores clássicos como Husserl, Heidgger, Espinosa, MerleauPonty ${ }^{6}$ e contemporâneos como Michel Serres, Morin, Atlan e Damásio ${ }^{7}$

\footnotetext{
4 Como, Ray Kurrzweil (2003), Minsky, Moravec, e G.S. Sussman (apud BRETON, 2003), Stelarc (2004)

5 Ver a esse respeito: Gaya (2005), in: Sociologias n. 13, ano 6, jan/jun, p. 324-336.

6 Husserl nas Investigações Lógicas (1975), Heidgger em Sobre o Humanismo (1973), Espinosa em Pensamentos Metafísicos (1973), Merleau-Ponty (1990).

7 Michel Serres (2005; 2004; 2001, 1994 e 1993), Morin (2003; 2001; 1991; 1986) , Atlan (1994) e Damásio (2003; 2000 e 1995).
} 
referências sólidas para a reinvenção dos corpos humanos. Inclusive e principalmente reinvenção dos corpos humanos nos discursos e práticas pedagógicas. Isto porque "Há um saber corpo... O corpo sabe o mundo, convive com ele. Sabe as coisas ao tocá-las. Conhece e reconhece. Os corpos comunicam-se, interpenetram-se" (Schüller, 2001, p.106). Nas palavras de Merleau-Ponty: "(...) porque sou esse animal de percepções e de movimentos que se chama corpo"(1975, p.438). Deseja-se compreender o corpo além dos dualismos mutilantes.

A rejeição do dualismo permite-nos começar da posição de um observador da corporeidade e sugere uma integração destes aspectos que são objetivamente acessíveis com aqueles que são subjetivamente experenciados. (Rintala, 1991, p. 261).

\section{2- A Origem do Conhecimento e a Reinvenção dos Corpos. Uma hipótese Serresseana}

Nenhuma aprendizagem evita a viagem. Sob a orientação de um guia, a educação empurra para o exterior. Parte: sai. Sai do ventre de tua mãe, do berço, da sombra oferecida pela casa paterna e as paisagens juvenis. Ao vento e a chuva: lá fora, faltam todos os abrigos. As tuas idéias iniciais não repetem senão palavras antigas. Jovem: velho tagarela. A viagem dos filhos, eis o sentido despido da palavra pedagogia. Aprender provoca a errância. (Serres, 1993, p.23).

Neste ensaio, tratamos do conhecimento, da aprendizagem e da relação ensino e aprendizagem. Pedagogia, a viagem dos filhos. Mas, quando se trata de refletir sobre o conhecimento, exige-se do pesquisador que recorra à epistemologia. Fizemos isso. Revisamos as principais teorias sobre 
a origem do conhecimento, presentes no debate acadêmico, teorias, que enfim, dão suporte às principais concepções pedagógicas. Mas revisamos a partir de uma curiosidade. A partir de uma questão orientadora: as principais correntes do pensamento epistemológico sobre a origem do conhecimento não estariam, da mesma forma que as correntes pedagógicas, necessitadas de reinventar os corpos humanos?

Para conjeturar sobre esta questão, vamos percorrer um breve trajeto sobre a da origem do conhecimento, a partir de três hipóteses: ${ }^{8}$ (a) a hipótese empirista; (b) a hipótese racionalista e (c) a hipótese construtivista.

Na hipótese empirista, conclui-se que não há qualquer patrimônio a priori da razão. Nossa consciência cogniscente não pode ter conteúdos retirados da razão. Nossa consciência retira seus conteúdos exclusivamente da experiência (do empírico). Como refere o filósofo português Leonardo Coimbra (Patrício, 1991): para o empirismo o conhecimento configura-se como o decalque da experiência, interpreta-se como imagem simétrica na reflexão de nossa consciência passiva de um mundo existente em si. ${ }^{9} \mathrm{O}$ conhecimento nos fornece "retratos" de objetos que existem fora de nós independentemente de nossos atos cognitivos (Da Costa,1997). Na Antigüidade, encontramos idéias empiristas nos sofistas e, mais tarde, especialmente entre os estóicos e os epicuristas. Nos estóicos encontramos pela primeira vez a comparação da alma como uma tábua por escrever (Hessen, 1987, p.70). Mas foi principalmente na filosofia inglesa dos séculos XVII e XVIII que o empirismo teve seu desenvolvimento sistematizado. Locke (1632

\footnotetext{
8 Em se tratando do estado atual dos conhecimentos sobre epistemologia, essas hipóteses representam uma importante simplificação teórica. Todavia a pretensão, aqui, é a de sublinhar as principais correntes sobre a origem do conhecimento para estimular a reflexão e definir algumas categorias de análise passíveis de acompanhar os argumentos expostos.

9 Da hipótese empirista decorre uma importante implicação para as teorias psicológicas e pedagógicas. Tendo em conta que não há qualquer a priori da razão sobre o conhecimento, conclui-se que o espírito humano em sua gênese pode ser representado por uma tábua rasa. Uma tábua lisa, onde a experiência deverá gravar o conhecimento. Tal pressuposto fundamenta as teorias psicológicas e pedagógicas comportamentalistas ou behavioristas. Modelar o sujeito. Modelar seu comportamento pela experiência. "Ensinar" através de estímulos e respostas, mediadas por reforços positivos e negativos. "Ensinar" na perspectiva do produto final, do comportamento previsto. Ensino programado, tarefas individuais programadas. Reforços, feedback. Evitar envolver-se com a "caixa preta". Enfim, modelar comportamentos objetivos a partir de moldes previamente definidos. Consultar sobre o tema: PINKER, S. Tábula Rasa. A negação contemporânea da natureza humana. São Paulo: Companhia das Letras, 2004.
} 
- 1704) opunha-se à teoria das idéias inatas. A alma é um papel em branco que a experiência cobre pouco a pouco com os traços da sua escrita (HESSEN, idibid). David Hume (1710 -1776) sugere diferenças entre impressões e idéias. As impressões são como sensações que temos quando ouvimos, tocamos. As idéias são representações que surgem baseadas nas impressões. São cópias das impressões. Para Hume, as idéias precedem as impressões. Condillacc (1715 - 1780) radicaliza o empirismo ao propor o sensualismo. Para este filósofo só há uma fonte de conhecimento: a sensação. A alma só tem originariamente uma faculdade: a de experimentar sensações. Todas as outras saíram desta. O pensamento não é mais do que uma faculdade apurada de experimentar sensações.

No século XIX, John Stuart Mill, atribui o conhecimento matemático sua raiz empírica ao afirmar:

Não há proposições a priori, válidas independentemente da experiência. Até as leis lógicas do pensamento têm a base de sua validade na experiência. Também elas não são mais do que generalizações da experiência passada (Hessen, 1987, id.ibid. p. 73).

A hipótese racionalista coloca o conjunto dos princípios do conhecimento na razão. Quando nossa razão julga que uma coisa tem que ser assim e que não pode ser de outro modo, só então, encontramo-nos ante um verdadeiro conhecimento. Uma das formas mais antigas de racionalismo se encontra em Platão. Nele está profundamente inserida a idéia de que os sentidos não podem conduzir-nos a um verdadeiro saber. Nos sentidos, nas percepções, na realidade empírica só podemos delinear evidências, opiniões, porém nunca o conhecimento verdadeiro. Platão propôs a chamada teoria da anamnésis. Esta teoria diz que todo conhecimento é uma reminiscência.

A alma contemplou as Idéias numa existência préterrena e recorda-se dela na ocasião da percepção sensível. Esta não tem, pois, a significação de um funda- 
mento do conhecimento espiritual, mas somente a significação de um estímulo. A medula deste racionalismo é a teoria da contemplação das idéias, a qual podemos denominar de racionalismo transcendente (Hessen, idibid, p,60).

Em Santo Agostinho (354 - 430), vamos encontrar um racionalismo teológico. Nele, todo o saber, no sentido próprio e rigoroso, procede da razão humana ou da iluminação divina. As verdades e os conceitos supremos são irradiados por Deus para o nosso espírito. Na modernidade surge outra forma de racionalismo. É a concepção das idéias inatas. Na Crítica da Razão Pura, Kant (1724 - 1804) afirma que nos é inato certo número de conceitos, justamente conceitos fundamentais do conhecimento. Tais conceitos não precedem da experiência, mas representam um patrimônio originário da razão. Para Descartes (1596 - 1650), esses conceitos são mais ou menos acabados. Para Leibniz (1646 - 1716), são potencialidades independentes da experiência.

Outra expressão do racionalismo evidencia-se no século XIX. O racionalismo lógico. Distingue-se dos anteriores, na medida em que se limita rigorosamente aos princípios da lógica formal. Esta forma de racionalismo vai constituir a pedra angular no neopositivismo da escola de Viena no qual se destacam: Ludwig Wittegensteisn (1889-1951) ${ }^{10}$ e Rudolf Carnap (1891 - 1970). A esfera da linguagem cumpre, de algum modo, o papel que a experiência tinha no empirismo clássico, ou seja, a de constituir o critério de investigação filosófica (Abbagnano, 1984, p.42).

\footnotetext{
10 Wittgenstein, filósofo austríaco de personalidade obsessiva. Imaginava não ser digno de viver entre humanos se não fosse capaz de escrever uma grande obra. Algumas vezes tentou o suicídio por não conseguir escrevê-la. Desfez-se de suas riquezas e se isolou numa pequena comunidade do interior como professor de crianças. Posteriormente alistou-se na Guerra como soldado. Mantinha sua obsessão. Aos 30 anos, apresenta sua obra prima "O Tratado Filosófico". Livro fundamental na concepção do positivismo lógico do Círculo de Viena. Mas, Wittgenstein surpreende a coletividade intelectual de seu tempo e passa a contestar radicalmente seu "Tratado". Transita de uma concepção racionalista para uma concepção relativista, expressa sob a teoria dos jogos ou códigos de linguagem.
} 
Na hipótese construtivista, pretende-se superar o dualismo ontológico entre o sujeito e o objeto, entre o ideal e o real e entre a experiência e a razão. O objeto existente no mundo real e a nossa experiência fundem-se na percepção sensorial e formarão, a partir daí, imagens que, em qualquer hipótese, serão reconstruídas e interpretadas em nossa mente. Portanto, não faz sentido imaginar o conhecimento fora desta relação dialética entre sujeito e objeto.

(...) o fenômeno do conhecer não pode ser equiparado à existência de fatos ou objetos lá fora, que podemos captar e armazenar na cabeça. A experiência de qualquer coisa lá fora é validada de modo especial pela estrutura humana, que torna possível a coisa que surge na descrição. (...) Tudo o que é dito, é dito por alguém (Maturana e Varela, 1985, p. 68 e 69).

Na visão construtivista, o conhecimento é uma ação. Ação que parte do sujeito que conhece em relação ao real. Experiência. Ação do e sobre o corpo. Não há conhecimento sem corpo (Damásio, 2003).

As imagens que construímos em nossa mente resultam de interações entre cada um de nós e os objetos que rodeiam os nossos organismos, interações que são mapeadas em padrões neurais e construídas de acordo com as capacidades do organismo (Damásio, 2003, p. 225).

Conforme Damásio, a imagem que vemos tem como base alterações que ocorrem nos nossos organismos, no corpo e no cérebro, conseqüentes a interações da estrutura física deste objeto particular com a estrutura física de nosso corpo. O conjunto de detectores sensoriais distribuídos em nosso corpo ajuda a construir os padrões neurais que mapeiam a interação multidimensional do organismo com o objeto.

Nesta concepção, a noção de conhecimento se diversifica. Exige-se um conhecimento biológico. Oriundo de um sujeito que é corpo-cérebro- 
mente, mas, um sujeito que, sendo corpo-cérebro-mente, produz, da mesma forma, um conhecimento psicológico. Um sujeito com seus sentimentos e emoções. Sentimentos e emoções que participam ativamente de todo o ato de conhecer. (Damásio, 1995; 2000 e 2003). Um conhecimento biológico e psicológico, mas também antropológico. Pois o sujeito nasce numa família, no seio de uma cultura, e carrega tradições. Tradições que formam sua visão de mundo (Morin, 1986). Um conhecimento que, sendo biológico, psicológico, antropológico é ainda sociológico. O sujeito vive em coletividades, é um sujeito político e ético. O conhecimento é, pois, biopsico-antropossocial (Morin, 1991, p. 19). Portanto, não há conhecimento sem corpo.

Como refere Morin (1986):

Todo o acontecimento cognitivo necessita da conjunção de processos energéticos, elétricos, químicos, fisiológicos, cerebrais, existenciais, psicológicos, culturais, lógicos, ideais, individuais, coletivos, pessoais, transpessoais e impessoais, que se engrenam uns nos outros. O conhecimento é, portanto, um fenômeno multidimensional, no sentido em que é, de maneira inseparável, ao mesmo tempo físico, biológico, mental, psicológico, cultural, social. (p. 15).

Em síntese: empirismo, realismo e construtivismo, teorias concorrentes sobre a origem do conhecimento. Através do empirismo acredita-se num saber objetivo independente de qualquer aprendizagem; pelo racionalismo, nada no conhecimento pode existir fora de nossa razão; no construtivismo o aprendiz, ao participar na construção do conhecimento, possibilita a síntese entre as concepções anteriores.

Mas, retomando a questão orientadora: essas principais correntes do pensamento epistemológico sobre a origem do conhecimento não estariam limitando a compreensão do próprio conhecimento às fronteiras da razão? 
Conhecimento será sinônimo de razão pura? Será conhecimento apenas o que é concebido pelas estruturas cerebrais do neocórtex? Será que as estratégias biológicas de regulação da vida, as emoções e os sentimentos (Damásio, 2000) não fazem parte desta história sobre a origem do conhecimento? Enfim, não estariam as principais correntes do pensamento epistemológico necessitadas de reinventar os corpos?

Michel Serres, discorre sobre essas questões. O autor afirma que nas principais correntes sobre a origem do conhecimento há um pressuposto:

Em todos esses sistemas a aprendizagem supõe uma compreensão clara do que se ensina, de acordo com o dogma de que não se pode aprender aquilo que não se compreende. Todo o conhecimento adquirido supõe uma explicação. (Serres, 2004, p.73).

Ora, percebe-se claramente na afirmação de Serres a crítica ao princípio do "cérebro num barril". Ou seja, só é conhecimento o que pode ser computado na lógica binária da razão formal. E, sublinhemos, este é um princípio assumido como uma tese forte entre os cientistas e artistas contemporâneos ligados a algumas correntes da Inteligência Artificial (Sterlac; Moravec; Kurrzweil). É com base neste princípio que os investigadores das correntes neo-humanistas têm a pretensão de escanear a mente para um computador e, com isso, substituir o corpo por uma máquina capaz de pensare solucionar problemas, de forma mais competente que os homens e as mulheres de corpo e alma. É o mundo de Matrix. Corpo obsoleto, portanto, descartável.

Todavia este é o princípio inerente à pedagogia tradicional que, na escola, reprime a plena expressão da corporalidade. É o suporte para uma pedagogia na qual o corpo humano, na escola, deve portar-se como uma estátua de mármore, como marionete, preso à frente da parede ao fundo da caverna, a ver imagens distorcidas do mundo, ou, quem sabe, corpos 
percebidos como avatares. Mas! Curiosamente, no discurso pedagógico contemporâneo, fala-se em complexidade.

Entretanto, como afirma Michel Serres (2004), e esta é uma hipótese relevante, em todos estes sistemas sobre a origem do conhecimento há um princípio que deve ser questionado.

Serres, afirma:

Sobre isso (a tese de que a aprendizagem supõe uma compreensão clara do que se ensina) não saberíamos grande coisa, a não ser compreender as grandiosas derrotas que o ensino sofreu em todos os países em que essa estupidez prevalece. Se tivesse sido necessário que eu compreendesse tudo o que me ensinaram no próprio momento do aprendizado, eu mal teria dominado a soma, o plural e o singular ou o nome da junção dos rios defronte dos quais minha família habitava. (Serres, 2004, p.73).

Ora! A supervalorização, a quase exclusividade, a arrogância da razão, como bem sabemos, advêm da era dos iluministas e de uma concepção de conhecimento, engendrado com o intuito de eliminar as trevas (SERRES, ibid.). No entanto, convenhamos:

Raramente temos conhecimento do que sabemos e do que não sabemos, estas duas enormes proezas da inteligência; o que ocorre com mais frequência é que sabemos o que não sabemos e sabemos mal o que sabemos. Supervalorizamos um cogito lúcido, tão raro quanto a iluminação de Newton em meio a seu pomar de maças ou a de Descartes em seu aquecido quarto na Alemanha. (Serres, id. ibid., p.74).

É importante recordar que sobrevivemos neste planeta como animais, mesmo antes de desenvolver a consciência. E sobrevivemos porque aprendemos. Desenvolvemos estratégias, criamos conhecimentos que nos per- 
mitiram permanecer na face da terra. Ou será que nossas emoções, nossos sentimentos não são eles próprios formas evidentes de conhecimentos? Os sentidos que nos permitem perceber os sons, os perfumes, os ritmos, as consistências e as cores não estão intimamente envolvidos nas operações de nosso conhecimento racional? Adaptamo-nos às exigências e sobrevivemos. Desenvolvemos conhecimentos. Evoluímos a partir de padrões de respostas relativamente simples e estereotipadas, que incluem regulação metabólica, os reflexos, os mecanismos biológicos subjacentes ao que irá tornar-se dor e prazer, impulsos e motivações. Evoluímos para padrões de respostas complexas e estereotipadas que incluem as emoções. Evoluímos para padrões sensoriais que assinalam dor, prazer e emoções que se transformam em imagens e produzem os sentimentos. Evoluímos para planos de resposta complexos, flexíveis e individualizados, que são formulados sob forma de imagens conscientes e podem ser executados como comportamentos, a razão superior (Damásio, 2000). De fato, atingimos o estágio da razão superior e, por outro lado, isto não pode significar reduzirmos nossos conhecimentos estritamente ao conhecimento racional. Esta é uma visão míope, reducionista, mutilada e mutilante. Não pode tal visão situarse no âmbito de um paradigma da complexidade. Reivindicar um conhecimento sem corpos é a própria negação da complexidade.

Portanto, nas questões sobre o conhecimento, na escola onde se exercitam o ensino e a aprendizagem, bem como na pedagogia, é necessário reinventar os corpos, pois são eles os sujeitos reais desta mescla de luz e sombra. O corpo recorda e esquece, pode mais e menos do que acredita poder, faz melhor ou pior do que sabe fazer, sabe e, ao mesmo tempo, não sabe, é como uma caixa preta às vezes entreaberta. Andem, corram, dancem, façam esporte, ginástica, teatro, pintem e bordem, vocês irão recuperar a fé, o corpo vai resolver a situação. O saber mergulha nele e dele ressurge. Oculto nas sombras, ele assimila lentamente o que foi simulado (Serres, id. ibid.). 
O corpo sabe coisas que a razão desconhece. O corpo esquece e recorda. É o corpo que nos leva pelos caminhos da pintura, da poesia, da música, da história, das ciências... O corpo não se esquece dos prazeres. Portanto, educar, tem tudo a ver com o corpo (Alves, ibibid).

Vejam o que quero mostrar: que não existe nada no conhecimento que não tenha estado primeiramente no corpo inteiro, cujas metamorfoses gestuais, posturais móveis e a própria evolução imitam tudo aquilo que o rodeia. (Serres, 2004, p.68).

Nosso saber tem origem no saber de outros que o aprendem a partir do nosso. Aí está o corpo. Corpo tão gestual quanto receptivo, mais ativo do que passivo, ósseo, muscular, cardiovascular, nervoso, ele é o portador dos cinco sentidos que dão significado às nossas aprendizagens. Este corpo está muito além dos limites sugeridos por uma pedagogia tradicional que o percebe apenas como um processador de informações. Como afirma Serres, o corpo encontra, assim, uma presença e uma função cognitiva própria, eliminadas nas teorias epistemológicas e na pedagogia tradicional pelo dualismo cartesiano. O corpo é plena atividade sensorial, portanto, convenhamos, nada pode existir no conhecimento que não tenha passado primeiramente pelo corpo. Receber, emitir, conservar, transmitir são, todos, atos especializados do corpo.

E nas nossas escolas? Bem! Os corpos só participam, brincam, jogam, dançam, fazem esporte, cantam e interpretam... após realizar seus deveres.

3. Pedagogia e complexidade. A reinvenção dos corpos

Como uma rápida decisão que elimina qualquer dúvida, os exigentes exercícios corporais são um ótimo início para um programa de filosofia básica: na alta mon- 
tanha, qualquer excitação, rotas equivocadas, mentiras ou má-fé equivalem à morte. Em contrapartida, a linguagem escrita ou falada repetida sem nenhum risco faz proliferar pessoas irrefletidas que, imóveis, se agitam e se reproduzem. (...) O risco que a verdade corre desaparece no instante em que o mundo inimitável exige posições, atos e movimentos cuja pertinência ele imediatamente sanciona. (Serres, 2004, p.12).

O problema de agora em diante é transformar a descoberta da complexidade em método da complexidade (Morin \& Moigne, 2000, p. 217). ${ }^{11}$ De fato, nós professores, necessitamos transformar em ação o discurso da complexidade. Numa práxis efetiva. Todavia, nesta pedagogia, por natureza complexa, não se pode prescindir de uma visão alargada do conhecimento. Uma visão que ultrapasse as fronteiras do exclusivamente racional. Exige-se um conhecimento que encontre suas raízes aquém e além da consciência. Um conhecimento impregnado de sentimentos e emoções. Um conhecimento mapeado a partir das marcas sobre o corpo. Devemos reconhecer que são os sentidos que nos permitem perceber, no toque sutil, a fragilidade de uma uva madura; é pelo olhar cuidadoso e sensível que nos emocionamos com as nuances das cores do céu no horizonte ao entardecer de um dia de verão; é pelos ouvidos que escolhemos a música que nos alegra a alma e nos faz dançar o corpo inteiro. Quem não aprende a discorrer sobre a qualidade de um bom vinho pelo buquê e pelo sabor que nos traz à memória lembranças de chocolate, frutas vermelhas ou carvalhos? O sabor está na origem do saber. A sensibilidade de nossos corpos freqüenta lugar privilegiado na origem do conhecimento. Não há conhecimento sem corpo. Não há pedagogia sem corpos. 
A origem do conhecimento, e não somente a do conhecimento intersubjetivo, mas também do objetivo reside no corpo. Não se pode conhecer qualquer pessoa ou coisa antes que o corpo adquira a forma, a aparência, o movimento, o "habitus", antes que ele com sua fisionomia entre em ação. (Serres, 2004, p. 68)

Por conseguinte, reivindicar uma pedagogia da complexidade exige a reinvenção dos corpos. Exige um conhecimento que parta de uma visão polissêmica e polimorfa de um corpo humano no mundo. Corpo que, pela pluralidade de sentidos e formas, configura-se em fonte privilegiada para exercitar a dialética e a dialógica inerentes ao pensamento complexo.

Mas, será esta tarefa assim tão difícil? Creio que não. Poderíamos iniciar por planejar uma outra escola. Talvez, uma escola cultural. Capaz de superar o modelo tradicional eminentemente enciclopédico e intelectualista herdado do Iluminismo. Uma escola que vá além da emancipação individualista de diferentes sujeitos a partir exclusivamente das suas necessidades e potencialidades psicológicas e biológicas excluídas de um contexto cultural. O caminho provavelmente é o de uma pedagogia de integrações. Integrações de conhecimentos e práticas. Conhecimentos científicos, filosóficos, artísticos, do senso comum. Pedagogia percebida numa perspectiva práticonormativa da formação de homens e mulheres na plenitude de sua humanidade. Uma pedagogia na qual possamos tratar o humano por inteiro. $\mathrm{O}$ humano na complexidade de sua corporalidade. O humano de corpo e alma, natural e cultural.

Sendo assim, vamos constituir nossas escolas com laboratórios, bibliotecas, salas de artes, ginásios e campos esportivos. Que nossas escolas incentivem a criação de corais, bandas de música, grupos de dança, folclore, teatro e circo, clubes de ciência, clubes de filosofia, clubes esportivos, clube de lazer, jornais. Enfim que nossas escolas e nossa pedagogia incenti- 
vem a vida. Aí, quem sabe, poderemos exercitar uma pedagogia da complexidade. Reinventar os corpos. É minha utopia!

\section{Referências}

ABBAGNANO, N. História da Filosofia. Lisboa, Ed. Presença, v. XIV, 1984.

ALTIERI, A. Um Corpo que se Move, Um Corpo que Aprende: A importância das atividades lúdicas e jogos no desenvolvimento infantil. Projeto de Trabalho de Conclusão de Curso apresentado à disciplina de Metodologia da Pesquisa no curso de Licenciatura em Educação Física da UFRGS. Porto Alegre, 2005.

ALVES, R. Educação dos Sentidos e mais... Campinas: Verus, 2005.

BRETON, D. Adeus ao Corpo. In. Novaes, A. O Homem- Máquina. A ciência manipula o corpo. São Paulo: Companhia das Letras. 2003.

CONDILACC, E. Tratado das Sensações. Campinas: Ed da Unicamp, 1993.

DA COSTA, N.C.A. Conhecimento Científico. São Paulo: Discurso Editorial, 1997.

DAMÁSIO, A. Ao Encontro de Espinosa. Mira-Cintra: Europa-América, 2003.

DAMÁSIO, A. O Erro de Descartes. Emoção, Razão e Cérebro Humano. 15ed. Men-Martins: Europa América, 1995.

DAMÁSIO, A. O Sentimento de Si. O Corpo, a Emoção e a Neurobiologia da Consciência. 5a ed. Mira-Cintra: Europa-América, 2000.

DESCARTES, R. Meditações. In Os Pensadores. Civita, V. (ed.) Trad. J. Guinsburg e Bento Prado Júnior. São Paulo: Abril Ed, 1973.

ESPINOSA, B. Pensamentos metafísicos. In. Os Pensadores. Civita, V. (ed.) Trad. Marilena Chauí. São Paulo: Abril Ed., 1973.

FREIRE, J.B. Ação Cultural para a Liberdade; e outros escritos. 5ed. Rio de Janeiro: Paz e Terra, 1982. 
GAYA, A. Discursos sobre o corpo ausente. In. Lebre.E \& Bento, J. Professor de Educação Física. Ofícios da Profissão. Porto: FCDEF.UP. 2004. GAYA, A . Será o corpo humano obsoleto? In: Sociologias n. 13, ano 6, jan/jun, p. 324336, Porto Alegre, PPGS/UFRGS, 2005.

HASSEN, J. Teoria do Conhecimento. $8^{\mathrm{a}}$ ed. Trad. António Correia. Coimbra: Arménio Amado,1987.

HEIDEGGER, M. Sobre o Humanismo. Carta a Jean Beaufret, Paris. In. Os Pensadores. Civita, V. (ed.). Trad. Ernildo Stein. São Paulo: Abril Ed., 1973.

HUSSERL, E. Investigações Lógicas. In. Os Pensadores. Civita, V. (ed.). Trad. Zeljko Loparíc e Andréa M.A.C. Loparíc. São Paulo: Abril Ed., 1975.

KURZWEILL, R. A Fusão Homem-Máquina. Estamos no Rumo de Matrix? In. Glen Yeffeth. A Pílula Vermelha: questões de ciência, filosofia e religião em Matrix. São Paulo: Publifolha, 2003.

LOCK, J. Ensaio Acerca do Entendimento Humano. In. Os Pensadores. Civita, V. (ed.) Trad. Anoar Aiex. São Paulo: Abril Ed., 1973.

MATURANA, H.; VARELA, F. A Árvore do Conhecimento. As bases biológicas do entendimento humano. Trad. Jonas Pereira dos Santos. Campinas, Ed. PSY. 1995.

MERLEAU-PONTY, M. Resumos de Cursos Psicossociologia e Filosofia. Trad. Constança Cesar. Campinas: Papirus, 1990.

MORIN, E. Introdução ao Pensamento Complexo. 4ed. Trad. Dulce Matos. Lisboa: Piaget, 2003.

MORIN, E. O Metodo III. O conhecimento do conhecimento/1. Trad. Maria Gabriela de Bragança. Mira-Cintra, Europa-América, 1986.

MORIN, E. O Método IV. As idéias: sua natureza, vida, habitat e organização. Trad. Emílio Campos Lima. Mira-Cintra, Europa-América, 1991.

MORIN. E. \& MOIGNE, J.L. A Inteligência da Complexidade. 3a . ed. Trad. Nurimar Maria Falci. São Paulo: Peirópolois, 2000.

PATRíClO, M. J. A Pedagogia de Leonardo Coimbra. Porto, Ed. Porto, 1991. 
PINKER, S Tábula Rasa. A negação contemporânea da natureza humana. Trad. Laura Texeira Mota. São Paulo: Companhia das Letras, 2004.

PLATÃO. Fédon. In. Os Pensadores. Civita, V. (ed.), Trad. Jorge Paleika e João Cruz Costa. São Paulo: Abril Ed., 1972.

SCHULLER. D. Heráclito e seu (dis)curso. Porto Alegre, L\&PM, 2001, p. 223. SERRES, M O Contrato Natural. Trad. Serafim Ferreira. Lisboa: Piaget, 1994.

SERRES, M Variações sobre o Corpo. Trad. Edgard de Assis Carvalho e Mariza Perassi Bosco. Rio de Janeiro: Bertand Brasil, 2004.

SERRES, M. O Incandescente. Trad. Edgard de Assis Carvalho e Mariza Perassi Bosco. Rio de Janeiro: Bertand Brasil, 2005

SERRES, M. O Terceiro Instruído. Trad. Serafim Ferreira. Lisboa: Piaget, 1993.

SERRES, M. Os Cinco Sentidos. Filosofia dos corpos misturados; 1. Trad. Eloá Jacobina. Rio de Janeiro: Bertand Brasil, 2001.

STELARC, O. <www.bmeworld.com/.../public/stelarc:sel/1.jpg> acessado em 02/ $07 / 2004$.

TARRIDE, M.I. Saúde Pública: uma complexidade anunciada. Rio de Janeiro: Ed. Fiocruz, 2002.

TOQUINHO. Canto pra Jade. In. Só tenho tempo para ser feliz. DVD Biscoito Fino. Sarapuí Produções Artísticas, 2005. 


\section{Resumo}

O objetivo deste ensaio é o de reivindicar a presença do corpo humano nas reflexões epistemológicas e pedagógicas. Parte-se da seguinte hipótese: Em tempos pós-modernos, os discursos filosófico e sociológico apontam para a superação da racionalidade iluminista. As propostas pedagógicas procuram perspectivas interdisciplinares, novas formas de configuração curricular e de organização do espaço escolar. Muito seguidamente ouvem-se referências a uma pedagogia da complexidade. Todavia, paradoxalmente, é nesta mesma escola e no âmbito dessa mesma pedagogia que o paradigma do racionalismo iluminista inspirador de uma educação intelectualista permanece, assumindo a herança cartesiana que concebe o corpo como simples extensão da mente. Três temas compõem os argumentos em defesa da hipótese orientadora: (1) Nas escolas de nosso tempo o corpo considerado como res extensa permanece passivo. Enfim, o corpo não vai à escola. (2) As principais correntes epistemológicas sobre a origem do conhecimento, da mesma forma, limitam-se a expressões de um conhecimento predominantemente racional. O corpo permanece ausente de interesse epistemológico. (3) Uma pedagogia que se limita ao exclusivamente racional é míope e, por conseqüência, não pode exigir configurar-se numa pedagogia da complexidade. É necessário recolocar os corpos na epistemologia, na pedagogia e nas escolas. É a reinvenção dos corpos.

Palavras-chaves: Pedagogia, corporeidade, epistemologia, educação.

Recebido: 01/12/2005

Aceite final: 05/01/2006 


\section{The reinvention of bodies - for a pedagogy of complexity}

\section{Adroaldo Gaya}

This essay is aimed at claiming the presence of the human body in epistemological and pedago gical reflections. It stars from the following hypothesis: in pre-modern times, the philosophical and sociological discourses point to an overcoming of enlightening rationality. The pedagogical proposals seek interdisciplinary perspectives, new forms of curricula configuration and organization of school space. References are often heard about a pedagogy of complexity. However, it is in that same school and within that same pedagogy that paradoxically the paradigm of Enlightenment's rationalism inspiring an intellectualist education remains, taking over the Cartesian heritage that conceives the body as a mere extension of mind. Three themes make up the arguments for the guiding hypothesis: (1) in the schools of our times, the body seen as res extensa remains passive. That is to say, the body does not go to school. (2) the main epistemological views on the origin of knowledge also limit themselves to the expression of predominantly rational knowledge. The body remains absent from epistemological interest. (3) A pedagogy limited to what is exclusively rational is shortsighted and therefore cannot demand to be configured as a pedagogy of complexity. It is necessary to place bodies within epistemology, pedagogy, and schools. It is the reinvention of bodies.

Key words: Pedagogy, corporality, epistemology, education. 